\title{
Separation of Rhenium (VII) and Vanadium (V) from Hydrochloric Acid Solutions by Solvent Extraction
}

\author{
Thi Hong Nguyen, Hoai Thanh Truong, and Man Seung Lee* \\ Department of Advanced Materials Science \& Engineering, Institute of Rare Metal, Mokpo National University, \\ Chonnam 58554, Republic of Korea
}

\begin{abstract}
The separation of $\operatorname{Re}(\mathrm{VII})$ and $\mathrm{V}(\mathrm{V})$ by solvent extraction with TBP was investigated by varying the $\mathrm{HCl}$, metal and chloride ion concentrations. Re(VII) was selectively extracted over V(V) from the HCl solution. The highest separation between Re(VII) and V(V) occurred at a concentration of $2.0 \mathrm{M} H C l$. The extraction reaction of $\operatorname{Re}(\mathrm{VII})$ by $\mathrm{TBP}$ was verified using the slope analysis method. Changing the concentration ratio of the two metals and the chloride ion concentration had little effect on the extraction of $\mathrm{V}(\mathrm{V})$. Re(VII) could be completely stripped from the loaded TBP when the $\mathrm{pH}$ of the stripping solution was higher than 3.0. The obtained results can be utilized to develop a process for separating Re(VII) and V(V) from $\mathrm{HCl}$ solutions.
\end{abstract}

(Received February 1, 2017; Accepted July 2, 2017)

Keywords: separation, rhenium, vanadium, tributyl phospate, solvent extraction

\section{INTRODUCTION}

Rhenium ( $\mathrm{Re}$ ) is widely used in oil refinery industries and the production of super alloys for high-temperature applications [1], while vanadium is an important metal in many technology fields, including steel alloys for aerospace, catalysts, machine tools, automotive, construction and nuclear reactor components [2,3]. Due to the growing demand for these metals, there are extensive efforts to recover them from several resources, such as ores [4], spent catalysts [5], and alloy scraps [6,7].

To recover of metals from these resources, a concentrated acid solution is first employed to dissolve the target metals [7-9]. After leaching, the target metal ions can be separated from impurities by several methods, such as solvent extraction [10-17], ion exchange [18], adsorption [19], and precipitation $[20,21]$. Among these methods, solvent extraction is widely employed to separate the target metals, because it is efficient and makes it possible to recover a pure solution [22-24]. According to the distribution diagram of $\operatorname{Re}(\mathrm{VII})$, anionic and neutral species of $\mathrm{Re}(\mathrm{VII})$, such as $\mathrm{ReO}_{4}{ }^{-}, \mathrm{HReO}_{4}$ and $\mathrm{ReO}_{3} \mathrm{Cl}$

*Corresponding Author: Man Seung Lee [Tel: +82-61-450-2492, E-mail: mslee@mokpo.ac.kr] Copyright (c) The Korean Institute of Metals and Materials are formed in the hydrochloric acid solution [22]. Cationic species of $\mathrm{VO}_{2}^{+}$exist at $\mathrm{pH}<2.0$, while anionic species, $\mathrm{VOCl}_{3}{ }^{-}$exist in an $\mathrm{HCl}$ concentration range of 2.0-3.0 M, while neutral complexes of $\mathrm{VO}_{2} \mathrm{Cl}$ can exist in a strong acid solution [23]. Many studies have investigated methods to extract rhenium and vanadium from strong acid solutions which contain individual metals, by using various extractants. Since most of the V(IV) exists as anionic species in a strong acid solution, amines (trioctyl amine (TOA) and trioctyl methylammonium chloride (Aliquat 336)) and solvating extractants (tributyl phosphate (TBP) and trioctylphosphine oxide (TOPO)) offer high extraction efficiency of V(IV) in an $\mathrm{HCl}$ concentration range of 0.1-10.0 M [15,25]. El-Nadi et al. reported that an $\mathrm{HCl}$ solution of (1.0-4.0 M) is suitable for the extraction of $\mathrm{V}(\mathrm{V})$ by Aliquat 336 [10]. The percentage of $\mathrm{Re}$ (VII) extraction by amines, such as TOA, trioctyl methyl ammonium chloride (TOMAC) and primary amine (Primene JMT) is higher than that obtained with solvating extractants, like TOPO and TBP, even at low acidity [26,16]. A high extraction percentage of $\operatorname{Re}(\mathrm{VII})$ by Cyanex 923 is obtained in an $\mathrm{HCl}$ concentration range of 2.0-3.0 M [22].

There are some resources, such as super alloys and alloy scraps, spent Pt-Re catalysts, and copper/molybdenum ores, which contain Re, V, Mo and W [11,27,28]. Although V, Mo, 


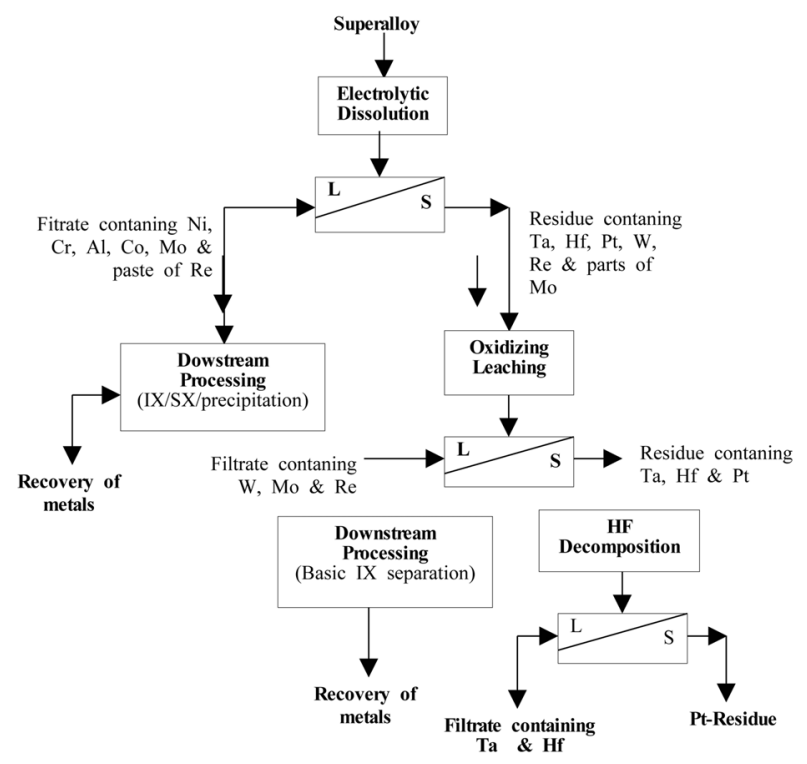

Fig. 1. Schematic diagram for recycling of superalloy scrap by hydrometallurgical route [32].

and $\mathrm{W}$ can be dissolved in an alkaline solution after soda roasting $[6,23,29]$, $\mathrm{Re}$ can be dissolved in high acid concentrations [30,31]. Nonetheless, it is difficult to dissolve all of the metals from alloy scraps by leaching. Therefore, a combined process consisting of electrochemical and hydrometallurgical operations seems a better option for dissolution of the metals from super alloys. A schematic diagram for the recycling of super alloy scrap by the hydrometallurgical route is shown in Fig. 1 [32]. To develop a process for separating these four metals from a hydrochloric acid solution, the separation of $\operatorname{Re}(\mathrm{VII})$ and $\mathrm{V}(\mathrm{V})$ was first investigated in this work. Since neutral species such as $\mathrm{HReO}_{4}, \mathrm{ReO}_{3} \mathrm{Cl}$ and $\mathrm{VO}_{2} \mathrm{Cl}$ exist in hydrochloric acid solutions [22], neutral extractants such as TBP, TOPO and a mixture of four trialkylphosphine oxides (Cyanex 923) offer high extraction efficiency for rhenium and vanadium from these solutions $[15,16,25,26]$. However, little information has been reported on the separation of $\mathrm{V}(\mathrm{V})$ and $\mathrm{Re}(\mathrm{VII})$ from hydrochloric acid solutions by neutral extractants. Moreover, the stripping of metals from the loaded TBP is fairly easy [13]. Therefore, in this work, TBP was employed to investigate the possibility of separating $\mathrm{Re}(\mathrm{VII})$ and $\mathrm{V}(\mathrm{V})$ from a moderate to strong $\mathrm{HCl}$ solution. The effect of $\mathrm{HCl}$ and chloride ion concentration on the separation behavior of $\mathrm{Re}(\mathrm{VII})$ and $\mathrm{V}(\mathrm{V})$ by TBP was investigated. An optimum condition was determined for the separation of $\operatorname{Re}(\mathrm{VII})$ and $\mathrm{V}(\mathrm{V})$. Moreover, the conditions for stripping the $\operatorname{Re}(\mathrm{VII})$ from the loaded TBP were also obtained.

\section{EXPERIMENTAL}

\subsection{Chemicals and reagents}

TBP (Yakuri Pure Chemical Co.) was used without further purification. Kerosene (Samchun Pure Chem Co.) was used as a diluent. Synthetic solutions of $\mathrm{V}(\mathrm{V})$ and $\operatorname{Re}(\mathrm{VII})$ were prepared by dissolving $\mathrm{NH}_{4} \mathrm{VO}_{3}$ (Sigma-Aldrich, 98\%) and $\mathrm{NH}_{4} \mathrm{ReO}_{4}$ (Sigma Co., 99\%) in distilled water. The acidity of the solution was adjusted by adding $\mathrm{HCl}$ (Daejung Chemicals \& Metals Co., 35\%) and $\mathrm{NaOH}$ (Duksan Co., 93\%). The concentration of chloride ion in the solution was adjusted by adding $\mathrm{NaCl}$ (Duksan Co., 99\%). NaSCN (Yakuri Pure Chemical Co., 98\%), $\mathrm{SnCl}_{2} \cdot 2 \mathrm{H}_{2} \mathrm{O}$ (Daejung Chemicals \& Metals Co., 97\%), $\mathrm{H}_{2} \mathrm{SO}_{4}$ (Duksan Pure Chemical Co., 98\%), $\mathrm{H}_{2} \mathrm{O}_{2}$ (Sigma-Aldrich, 35\%) were used to prepare the solutions necessary to measure the concentration of metal ions.

\subsection{Solvent extraction process}

Extraction and stripping experiments were carried out by mixing equal volumes $(10 \mathrm{~mL})$ of the aqueous and organic phases for $30 \mathrm{~min}$ (extraction and stripping equilibrium were reached within $30 \mathrm{~min}$ in initial tests) using a wrist action shaker (Burrell model 75, USA). After shaking, the organic and aqueous phase was separated using separating funnels. All experiments were performed at room temperature $(25 \pm$ $\left.1.0{ }^{\circ} \mathrm{C}\right)$.

\subsection{Measurement of the metal ion concentration}

Rhenium and vanadium ion concentrations in the aqueous phase before and after extraction were determined using an inductively coupled atomic emission spectrometer (ICP-AES, OPTIMA 4300 DV, PerkinElmer Inc., USA) or ultraviolet Spectrophotometer (UV-1800, Shimadzu, Japan). The concentration of metal ions in the loaded organic phase was calculated by mass balance. The distribution ratio (D) was 


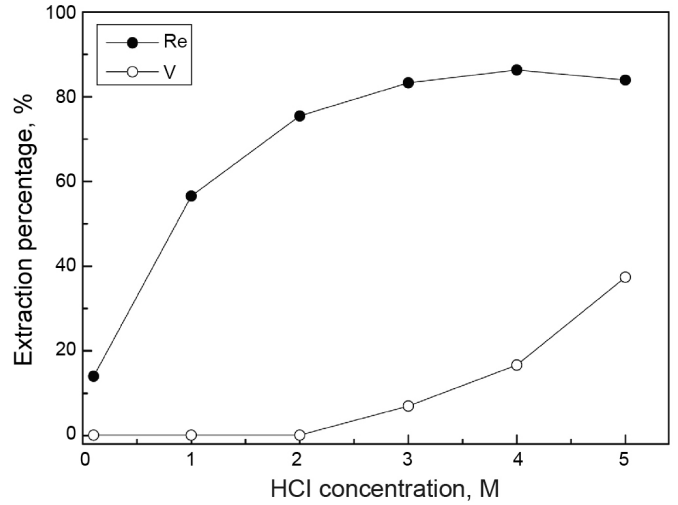

Fig. 2. Effect of $\mathrm{HCl}$ concentration on extraction of $\mathrm{Re}(\mathrm{VII})$ and $\mathrm{V}(\mathrm{V})$ by TBP. Aqueous: $\mathrm{Re}(\mathrm{VII})=\mathrm{V}(\mathrm{V})=100 \mathrm{mg} / \mathrm{L},[\mathrm{HCl}]=0.1-5.0$ $\mathrm{M} ;[\mathrm{TBP}]=1.0 \mathrm{M} ; \mathrm{O} / \mathrm{A}=1$; Diluent: kerosene.

calculated as the concentration of metal present in the organic phase to that present in the aqueous phase at equilibrium. The separation factor was calculated from the ratio of the distribution coefficient.

Preparation of samples for ultraviolet spectrophotometer: $1 \mathrm{~mL}$ of $\operatorname{Re}(\mathrm{VII})$ test solution with a $\mathrm{Re}$ (VII) concentration range of $(0-100 \mathrm{mg} / \mathrm{L})$ was placed into graduated flasks $(\mathrm{V}=20 \mathrm{~mL}$ ). Then $8 \mathrm{~mL}$ of $4.0 \mathrm{M} \mathrm{HCl}, 2 \mathrm{~mL}$ of $1.6 \mathrm{M} \mathrm{NaSCN}$ and $1 \mathrm{~mL}$ of $1.0 \mathrm{M} \mathrm{SnCl}_{2} \cdot 2 \mathrm{H}_{2} \mathrm{O}$ in $2.0 \mathrm{M} \mathrm{HCl}$ were added, and the solutions were brought up to a flask mark with distilled water and measured at $432 \mathrm{~nm}$ [33]. In the case of the $\mathrm{V}(\mathrm{V}), 1 \mathrm{~mL}$ of $\mathrm{V}(\mathrm{V})$ test solution in the $\mathrm{V}(\mathrm{V})$ concentration range of $(0-100 \mathrm{mg} / \mathrm{L})$ was graduated into flasks $\left(\mathrm{V}=20 \mathrm{~mL}\right.$ ) and $4 \mathrm{~mL}$ of $5.0 \mathrm{M} \mathrm{H}_{2} \mathrm{SO}_{4}$ and $0.5 \mathrm{~mL}$ of $3 \% \mathrm{H}_{2} \mathrm{O}_{2}$ were added. The solutions were brought up to a flask mark with distilled water and measured at $450 \mathrm{~nm}$ [34].

\section{RESULTS AND DISCUSSION}

\subsection{Effect of $\mathrm{HCl}$ concentration}

Since the composition of $\operatorname{Re}(\mathrm{VII})$ and $\mathrm{V}(\mathrm{V})$ in secondary resources is very low $(\leq 100 \mathrm{mg} / \mathrm{L})$ [6,35-36], a synthetic solution containing $100 \mathrm{mg} / \mathrm{L}$ of $\operatorname{Re}(\mathrm{VII})$ and $\mathrm{V}(\mathrm{V})$ was prepared in these experiments. The $\mathrm{HCl}$ concentration of the synthetic solution was varied from 0.1 to $5.0 \mathrm{M}$ and TBP concentration was fixed at $1.0 \mathrm{M}$. The volume ratio of organic and aqueous phase was unity and the obtained results are shown in Fig. 2. Re(VII) was selectively extracted over V(V)
Table 1. Effect of $\mathrm{HCl}$ concentration on separation factor between $\operatorname{Re}(\mathrm{VII})$ and V(V) by TBP

\begin{tabular}{cc}
\hline$[\mathrm{HCl}], \mathrm{M}$ & $\mathrm{SF}=\mathrm{D}_{\mathrm{Re}(\mathrm{VII})} / \mathrm{D}_{\mathrm{V}(\mathrm{V})}$ \\
\hline 0.1 & 114 \\
\hline 1.0 & 864 \\
\hline 2.0 & 2137 \\
\hline 3.0 & 70 \\
\hline 4.0 & 30 \\
\hline 5.0 & 8
\end{tabular}

Aqueous solution, $\mathrm{mg} / \mathrm{L}: \mathrm{Re}(\mathrm{VII})-100, \mathrm{~V}(\mathrm{~V})-100.0 ;[\mathrm{HCl}]=0.1-5.0$ $\mathrm{M} ;[\mathrm{TBP}]=1.0 \mathrm{M}$; Diluent: kerosene; $\mathrm{O} / \mathrm{A}=1: 1$.

by TBP from the $\mathrm{HCl}$ solution. The extraction percentage of $\mathrm{Re}(\mathrm{VII})$ increased from 14.0 to $83.3 \%$ as the $\mathrm{HCl}$ concentration increased from 0.1 to $3.0 \mathrm{M}$, and then was constant with the further increases in $\mathrm{HCl}$ concentration to 5.0 M. The distribution diagram of $\operatorname{Re}(\mathrm{VII})$ [22] indicates that the mole fraction of $\mathrm{HReO}_{4}$ increases in an $\mathrm{HCl}$ concentration of 1.0-3.0 $\mathrm{M}$ and then slowly decreases with further increase in $\mathrm{HCl}$ concentration. Although the relative distribution of $\mathrm{HReO}_{4}$ decreases in the higher acid concentration, another neutral species, $\mathrm{ReO}_{3} \mathrm{Cl}$ is formed in strong $\mathrm{HCl}$ concentration [22]. Therefore, the extraction percentage of $\mathrm{Re}(\mathrm{VII})$ by TBP was constant over the $\mathrm{HCl}$ concentration range of 3.0-5.0 M. The extraction behavior of Re(VII) by TBP in this work is in good agreement with the distribution diagram of $\operatorname{Re}(\mathrm{VII})$.

In the case of $\mathrm{V}(\mathrm{V})$, the extraction percentage of $\mathrm{V}(\mathrm{V})$ was negligible in the $\mathrm{HCl}$ concentration range of 0.1-2.0 M because most of $\mathrm{V}(\mathrm{V})$ exists as $\mathrm{VO}_{2}^{+}$. When the $\mathrm{HCl}$ concentration is increased from 3.0 to $5.0 \mathrm{M}$, a small amount of $\mathrm{VO}_{2} \mathrm{Cl}$ forms [23] and as a result the extraction percentage of the $\mathrm{V}(\mathrm{V})$ increased from 6.7 to $39.2 \%$. The solvent extraction of $\operatorname{Re}(\mathrm{VII})$ and $\mathrm{V}(\mathrm{V})$ by $\mathrm{TBP}$ in the hydrochloric acid solution can be represented as follows $[25,26,37]$.

$$
\begin{aligned}
& \mathrm{H}^{+}+\mathrm{ReO}_{4}{ }^{-}+3 \mathrm{TBP}_{(\mathrm{org})}=(\mathrm{TBP})_{3} \cdot \mathrm{HReO}_{4}(\text { org }) \\
& \mathrm{ReO}_{3} \mathrm{Cl}+4 \mathrm{TBP}_{(\text {org })}=(\mathrm{TBP})_{4} \cdot \mathrm{ReO}_{3} \mathrm{Cl}(\text { org }) \\
& \mathrm{VO}_{2} \mathrm{Cl}+\mathrm{nTBP}_{(\text {org })}=(\mathrm{TBP})_{\mathrm{n}} \cdot \mathrm{VO}_{2} \mathrm{Cl}_{(\text {org })}
\end{aligned}
$$

where $\mathrm{n}=1$ or 2 , and subscript (org) represents organic 


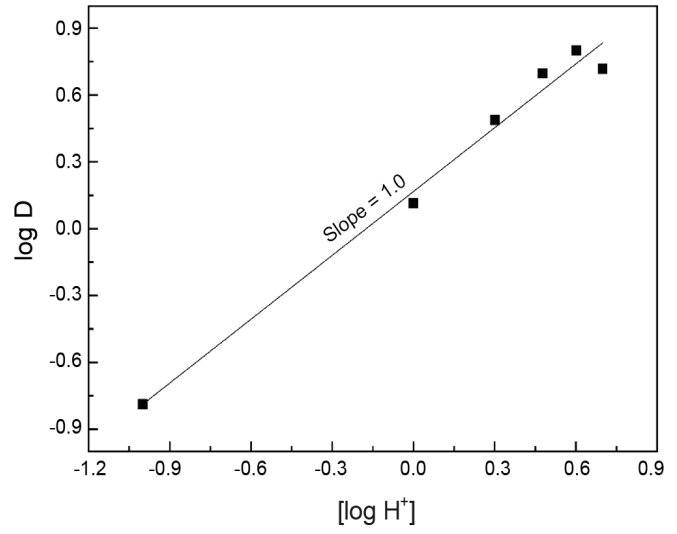

Fig. 3. Plot of $\log \mathrm{D}$ vs $\log \left[\mathrm{H}^{+}\right]$. Aqueous: $\mathrm{Re}(\mathrm{VII})=100 \mathrm{mg} / \mathrm{L}$, $[\mathrm{HCl}]=0.1-5.0 \mathrm{M} ;[\mathrm{TBP}]=1 ; \mathrm{O} / \mathrm{A}=1$; Diluent: kerosene.

phase.

The obtained results indicate that the separation efficiency of $\mathrm{Re}(\mathrm{VII})$ and $\mathrm{V}(\mathrm{V})$ strongly depends on the $\mathrm{HCl}$ concentration. Table 1 shows the variation in the separation factor between $\mathrm{Re}(\mathrm{VII})$ and $\mathrm{V}(\mathrm{V})$ with $\mathrm{HCl}$ concentration. The separation factor between $\operatorname{Re}(\mathrm{VII})$ and $\mathrm{V}(\mathrm{V})$ increased with the increase in $\mathrm{HCl}$ concentration from 0.1 to $2.0 \mathrm{M}$, and then decreased with the further increase in $\mathrm{HCl}$ concentration due to the co-extraction of $\mathrm{V}(\mathrm{V})$. The highest separation of $\mathrm{Re}(\mathrm{VII})$ and $\mathrm{V}(\mathrm{V})$ occurred at $2.0 \mathrm{M} \mathrm{HCl}$. The plot of $\log \mathrm{D}$ and $\log \left[\mathrm{H}^{+}\right]$is shown in Fig. 3. The value of the slope was unity, implying that one mole of hydrogen ions took part in the extraction. The hydrogen ions can associate with the $\mathrm{ReO}_{4}{ }^{-}$ species to form $\mathrm{HReO}_{4}$ which can be extracted by TBP [22]. The obtained results shown in Fig. 3 agree well with Eq. (1).

When extracting with TBP, TBP often replaces the water in the hydration sphere of a metal ion, where water acts as a bridging supporter to form organic-metal complexes through hydrogen bonding $[38,39]$. The number of displaced water molecules during extraction with TBP depends on the nature of the metal ions and the acidity of the aqueous solution. In order to obtain information about the number of displaced water molecules during the extraction, it is necessary to measure the change in mass of the aqueous phase before and after the extraction. In this work, the change in mass of the aqueous phase was not measured. Therefore, the displacement of water during the extraction with TBP was not considered in Eqs. (1)-(3).

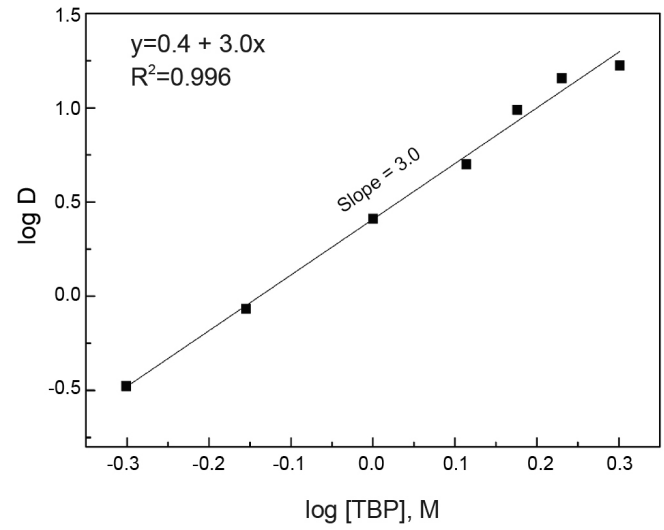

Fig. 4. Plot of $\log \mathrm{D}$ vs $\log [\mathrm{TBP}]$. Aqueous: $\mathrm{Re}(\mathrm{VII})=100 \mathrm{mg} / \mathrm{L}$, $[\mathrm{HCl}]=2.0 \mathrm{M} ;[\mathrm{TBP}]=0.5-2.0 \mathrm{M} ; \mathrm{O} / \mathrm{A}=1$; Diluent: kerosene.

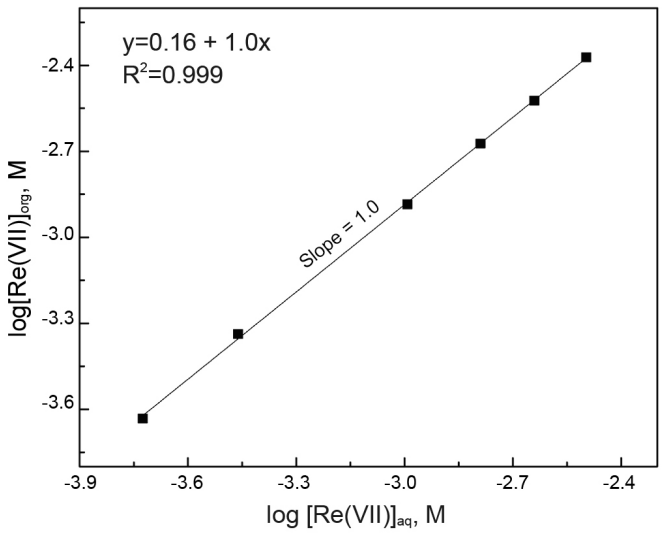

Fig. 5. Plot of $\log [\operatorname{Re}(\mathrm{VII})]_{\mathrm{aq}}, \mathrm{M}$ vs $\log [\operatorname{Re}(\mathrm{VII})]_{\text {org. Aqueous: }}$ $\operatorname{Re}(\mathrm{VII})=50-1000 \mathrm{mg} / \mathrm{L},[\mathrm{HCl}]=2.0 \mathrm{M} ;[\mathrm{TBP}]=1.0 \mathrm{M} ; \mathrm{O} / \mathrm{A}=1 ;$ Diluent: kerosene.

The solvent extraction reaction of $\mathrm{Re}$ (VII) by TBP in 2.0 $\mathrm{M} \mathrm{HCl} \mathrm{solution} \mathrm{was} \mathrm{verified} \mathrm{by} \mathrm{applying} \mathrm{a} \mathrm{slope} \mathrm{analysis}$ method and the results are shown in Figs. 4 and 5. First, the concentration of TBP was varied from 0.5 to $2.0 \mathrm{M}$ and the TBP phase was contacted with the synthetic solution containing $100 \mathrm{mg} / \mathrm{L}$ of $\mathrm{Re}(\mathrm{VII})$ in $2.0 \mathrm{M} \mathrm{HCl}$. Figure 4 shows the plot of $\log$ [TBP] vs. $\log \mathrm{D}$ for the extraction data. The slope of this plot was three, indicating that three moles of TBP take part in the solvent extraction reaction of one mole of $\operatorname{Re}(\mathrm{VII})$ which is in good agreement with Eq. (1). In the present study, $100 \mathrm{mg} / \mathrm{L} \operatorname{Re}(\mathrm{VII})$ was employed and thus about $0.002 \mathrm{M}$ TBP was needed. However, the extraction percentage of $\operatorname{Re}(\mathrm{VI})$ was very low when the TBP concentration was less than $0.1 \mathrm{M}$, due to the extraction of 


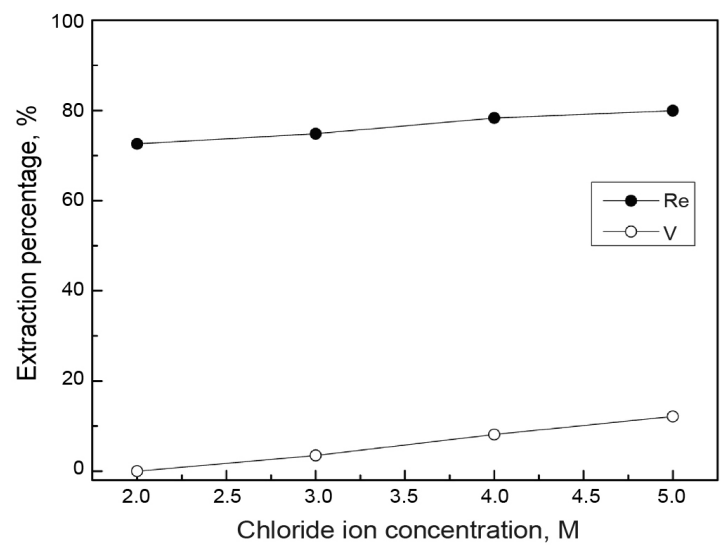

Fig. 6. Effect of chloride ion concentration on extraction of $\mathrm{Re}(\mathrm{VII})$ and $\mathrm{V}(\mathrm{V})$ from $2.0 \mathrm{M} \mathrm{HCl}$ solution. Aqueous: $\operatorname{Re}(\mathrm{VII})=\mathrm{V}(\mathrm{V})=100 \quad \mathrm{mg} / \mathrm{L} ; \quad\left[\mathrm{Cl}^{-}\right]=2.0-5.0 \quad \mathrm{M} ; \quad[\mathrm{TBP}]=1.0 \quad \mathrm{M}$; $\mathrm{O} / \mathrm{A}=1$; Diluent: kerosene.

$\mathrm{HCl}$ by TBP [15]. Therefore, $1 \mathrm{M}$ TBP was employed in further experiments to verify the complete extraction of $\operatorname{Re}(\mathrm{VII})$.

In order to check the possibility of polymerization of the extracted Re(VII) species in TBP, the initial concentration of $\mathrm{Re}(\mathrm{VII})$ was varied from 50 to $1000 \mathrm{mg} / \mathrm{L}$. This aqueous phase was extracted using 1.0 M TBP. The plot of log $[\operatorname{Re}(\mathrm{VII})]_{\text {aq }}$ vs. $\log [\operatorname{Re}(\mathrm{VII})]_{\text {org }}$ produced a straight line with a slope of unity (see Fig. 5), indicating that the extracted $\operatorname{Re}(\mathrm{VII})$ species exist as a monomer in the TBP in our experimental conditions. From the obtained results, it can be concluded that the extraction reaction of $\operatorname{Re}(\mathrm{VII})$ by TBP in the present study follows Eq. (1).

\subsection{Effect of chloride concentration}

The concentration of chloride ions can affect the distribution of a metal ion in $\mathrm{HCl}$ solution. Generally, an increase in chloride ion concentration favors the formation of electrically neutral and anionic species $[25,26]$. Therefore, it was anticipated that the separation behavior of $\operatorname{Re}(\mathrm{VII})$ and $\mathrm{V}(\mathrm{V})$ by TBP would be affected by the variation in the concentration of chloride ion. Hence, the effect of chloride ion concentration on the separation of $\operatorname{Re}(\mathrm{VII})$ and $\mathrm{V}(\mathrm{V})$ by TBP was investigated in the present study. For this purpose, the concentration of chloride ion in a synthetic solution containing $100 \mathrm{mg} / \mathrm{L}$ of $\mathrm{Re}(\mathrm{VII})$ and $\mathrm{V}(\mathrm{V})$ was varied from 2.0 to $5.0 \mathrm{M}$ by adding $\mathrm{NaCl}$. In these experiments, the
Table 2. Effect of chloride ion concentration on separation factor between $\mathrm{Re}(\mathrm{VII})$ and $\mathrm{V}(\mathrm{V})$ by TBP

\begin{tabular}{cc}
\hline$[\mathrm{Cl}], \mathrm{M}$ & $\mathrm{SF}=\mathrm{D}_{\mathrm{Re}(\mathrm{VII})} / \mathrm{D}_{\mathrm{V}(\mathrm{V})}$ \\
\hline 2.0 & 2137 \\
\hline 3.0 & 83 \\
\hline 4.0 & 41 \\
\hline 5.0 & 29
\end{tabular}

Aqueous solution, $\mathrm{mg} / \mathrm{L}$ : $\mathrm{Re}(\mathrm{VII})-100.0, \mathrm{~V}(\mathrm{~V})-100.0 ;[\mathrm{Cl}]=2.0-5.0 \mathrm{M} ;[\mathrm{H}+]=2.0 \mathrm{M}$; $[\mathrm{TBP}]=1.0 \mathrm{M}$; Diluent: kerosene; $\mathrm{O} / \mathrm{A}=1: 1$.

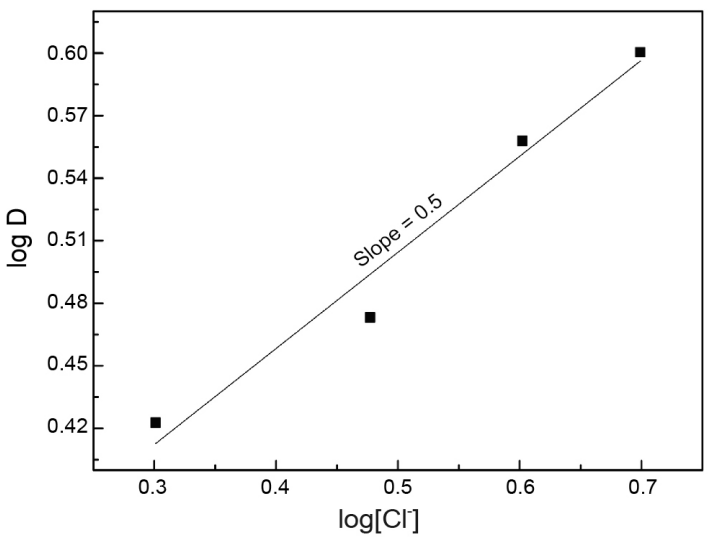

Fig. 7. Plot of $\log \mathrm{D}$ vs $\log \left[\mathrm{Cl}^{-}\right]$. Aqueous: $\mathrm{Re}(\mathrm{VII})=100 \mathrm{mg} / \mathrm{L}$, $[\mathrm{HCl}]=2.0 \mathrm{M} ;[\mathrm{TBP}]=1.0 ; \mathrm{O} / \mathrm{A}=1 ;$ Diluent: kerosene.

concentration of $\mathrm{HCl}$ and $\mathrm{TBP}$ was fixed at 2.0 and $1.0 \mathrm{M}$, respectively. Figure 6 shows the variation in extraction percentage of $\operatorname{Re}(\mathrm{VII})$ and $\mathrm{V}(\mathrm{V})$ with chloride ion concentration. The extraction percentage of $\mathrm{Re}(\mathrm{VII})$ and $\mathrm{V}(\mathrm{V})$ slowly increased from 72.6 and $0.3 \%$ to 79.9 and $12.1 \%$, respectively with the increase in chloride ion concentration from 2.0 to $5.0 \mathrm{M}$. Compared to the increase in chloride ion concentration, the increase in the extraction percentage of both metals was insignificant. Table 2 shows the variation in separation factor between $\mathrm{Re}(\mathrm{VII})$ and $\mathrm{V}(\mathrm{V})$ with chloride ion concentration. The separation factor between $\operatorname{Re}(\mathrm{VII})$ and $\mathrm{V}(\mathrm{V})$ reached a peak at a chloride ion concentration of $2.0 \mathrm{M}$ and then decreased with further increases in chloride ion concentration. The plot of $\log \mathrm{D}$ and $\log \left[\mathrm{Cl}^{-}\right]$is shown in Fig. 7. According to the data, the slope was approximately unity, indicating that one mole of chloride ion was involved in the extraction.

\subsection{Effect of $\mathrm{V}(\mathrm{V})$ and $\mathrm{Re}(\mathrm{VII})$ concentration}

The separation efficiency of two metals may be affected by 


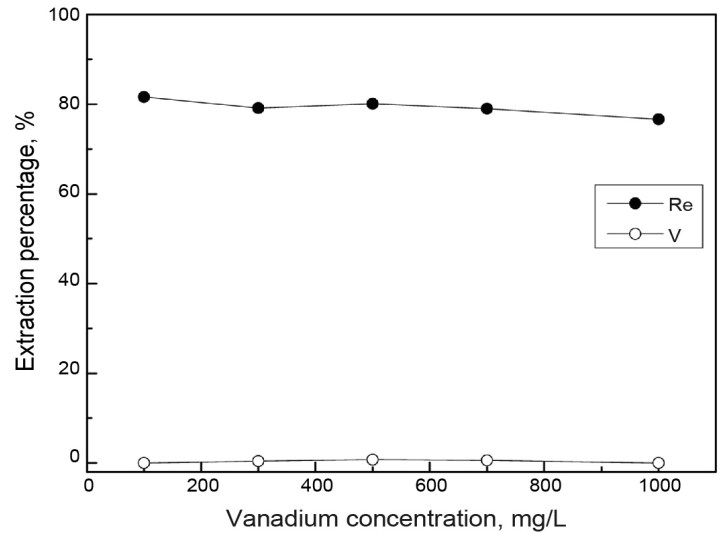

Fig. 8. Effect of vanadium concentration on extraction of $\operatorname{Re}(\mathrm{VII})$ and $\mathrm{V}(\mathrm{V})$ from $2.0 \mathrm{M} \mathrm{HCl}$ solution. Aqueous: $\mathrm{Re}(\mathrm{VII})=100 \mathrm{mg} / \mathrm{L}$, $[\mathrm{V}]=100-1000 \mathrm{mg} / \mathrm{L} ;[\mathrm{TBP}]=1.0 \mathrm{M} ; \mathrm{O} / \mathrm{A}=1$; Diluent: kerosene.

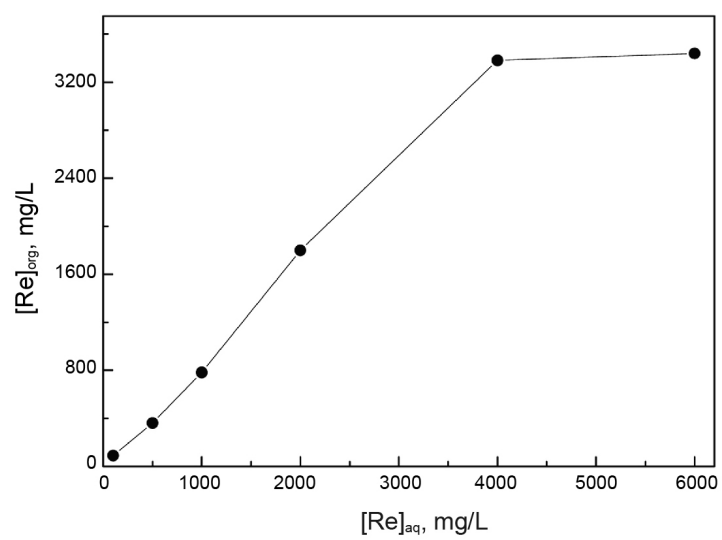

Fig. 9. Loading capacity of $1 \mathrm{M}$ TBP for $\mathrm{Re}(\mathrm{VII})$. Aqueous: $[\mathrm{Re}]=100-6000 \mathrm{mg} / \mathrm{L},[\mathrm{V}]=100 \mathrm{mg} / \mathrm{L},[\mathrm{HCl}]=2.0 \mathrm{M}$; $[\mathrm{TBP}]=1.0$ M; Diluent: kerosene.

the concentration ratio of the two metals. Therefore, the effect of vanadium concentration on the extraction and separation behavior of $\operatorname{Re}(\mathrm{VII})$ and $\mathrm{V}(\mathrm{V})$ was investigated by varying vanadium concentration from 100 to $1000 \mathrm{mg} / \mathrm{L}$. The Re(VII) and $\mathrm{HCl}$ concentration in the solution were fixed at $100 \mathrm{mg} / \mathrm{L}$ and 2.0 M, respectively. These experiments were carried out using 1.0 M TBP and the results are shown in Fig. 8. The extraction percentage of $\operatorname{Re}(\mathrm{VII})$ was constant at $80.0 \%$, while that of $\mathrm{V}(\mathrm{V})$ was negligible at any vanadium concentration range. Figure 8 indicates that the vanadium concentration in the mixed solution did not affect the extraction and separation behavior of $\operatorname{Re}(\mathrm{VII})$ and $\mathrm{V}(\mathrm{V})$ when using TBP.

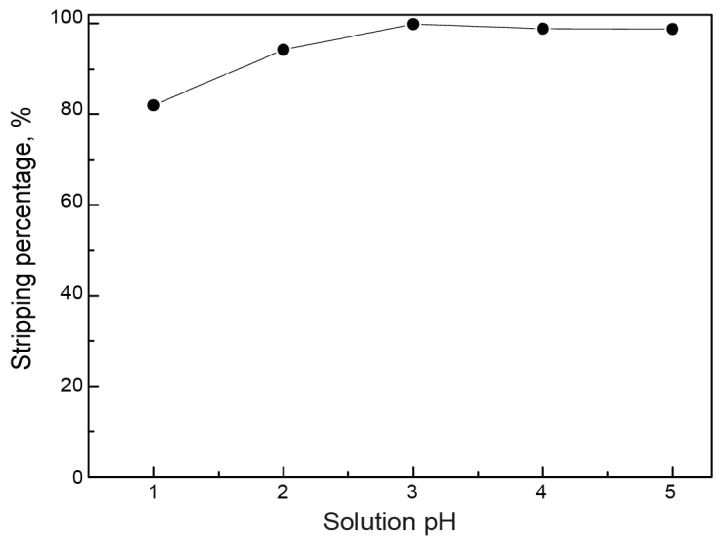

Fig. 10. Effect of solution $\mathrm{pH}$ of $\mathrm{HCl}$ solution on the stripping of $\operatorname{Re}(\mathrm{VII})$ from the loaded TBP. Loaded organic: $\operatorname{Re}(\mathrm{VII})=76.5$ $\mathrm{mg} / \mathrm{L}, \mathrm{O} / \mathrm{A}=1$.

The effect of $\operatorname{Re}(\mathrm{VII})$ concentration on the extraction behavior of $\operatorname{Re}(\mathrm{VII})$ and $\mathrm{V}(\mathrm{V})$ was investigated by varying $\operatorname{Re}(\mathrm{VII})$ concentrations from 100 to $6000 \mathrm{mg} / \mathrm{L}$. The $\mathrm{V}(\mathrm{V})$ and $\mathrm{HCl}$ concentrations were fixed at $100 \mathrm{mg} / \mathrm{L}$ and $2.0 \mathrm{M}$, respectively. Figure 9 shows the variation in extraction percentage of $\operatorname{Re}(\mathrm{VII})$ and $\mathrm{V}(\mathrm{V})$ with rhenium concentration. The extraction percentage of $\operatorname{Re}(\mathrm{VII})$ decreased from 82.9 to $68.7 \%$ as the initial concentration of $\operatorname{Re}(\mathrm{VII})$ increased. However, in these experiments, no $\mathrm{V}(\mathrm{V})$ was extracted and thus complete separation of the two metals was possible.

\subsection{Stripping}

It can be seen in Fig. 2 that the extraction of $\operatorname{Re}(\mathrm{VII})$ decreased with the decrease in $\mathrm{HCl}$ concentration. Therefore, a weak $\mathrm{HCl}$ solution was employed to strip $\mathrm{Re}(\mathrm{VII})$ from the loaded TBP. For this purpose, the $\mathrm{pH}$ of the $\mathrm{HCl}$ solution was controlled from 1.0 to 5.0 by using $\mathrm{NaOH}$. In these experiments, the loaded TBP was prepared by extracting an aqueous solution containing $100 \mathrm{mg} / \mathrm{L}$ of $\operatorname{Re}(\mathrm{VII})$ and $\mathrm{V}(\mathrm{V})$ at 2.0 $\mathrm{M} \mathrm{HCl}$ with $1.0 \mathrm{M}$ TBP. The concentration of $\operatorname{Re}(\mathrm{VII})$ in the loaded TBP was $76.5 \mathrm{mg} / \mathrm{L}$, while no $\mathrm{V}(\mathrm{V})$ was extracted at this condition. Figure 10 shows the variation in the stripping percentage of $\operatorname{Re}(\mathrm{VII})$ from the loaded TBP with solution $\mathrm{pH}$. The stripping percentage of $\operatorname{Re}(\mathrm{VII})$ increased from $82.0 \%$ to $99.8 \%$ with the increase in $\mathrm{pH}$ from 1.0 to 3.0 and then was constant with further increases in solution $\mathrm{pH}$.

$\operatorname{Re}(\mathrm{VII})$ was selectively extracted over $\mathrm{V}(\mathrm{V})$ from a $2.0 \mathrm{M}$ 
$\mathrm{HCl}$ solution with a high separation factor of 2137. Moreover, the $\operatorname{Re}(\mathrm{VII})$ in the loaded TBP was completely stripped from the loaded TBP using a weak $\mathrm{HCl}$ solution. Based on the results obtained in this work, a simple and economical process can be developed for the separation of $\operatorname{Re}(\mathrm{VII})$ and $\mathrm{V}(\mathrm{V})$ from $\mathrm{HCl}$ solution by solvent extraction with TBP.

\section{CONCLUSION}

The separation of $\operatorname{Re}(\mathrm{VII})$ and $\mathrm{V}(\mathrm{V})$ by solvent extraction with TBP from solutions containing moderate to strong $\mathrm{HCl}$ and $100 \mathrm{mg} / \mathrm{L}$ of $\operatorname{Re}(\mathrm{VII})$ and $\mathrm{V}(\mathrm{V})$ was investigated. $\mathrm{Re}(\mathrm{VII})$ was selectively extracted by TBP in the $\mathrm{HCl}$ concentration range from 0.1 to $5.0 \mathrm{M}$, while in that range the extraction percentage of $\mathrm{V}(\mathrm{V})$ was low. The separation factor between $\mathrm{Re}(\mathrm{VII})$ and $\mathrm{V}(\mathrm{V})$ increased with an increase in $\mathrm{HCl}$ concentration from 0.1 to $2.0 \mathrm{M}$, and then decreased with further increases in $\mathrm{HCl}$ concentration, due to the co-extraction of $\operatorname{Re}(\mathrm{VII})$ andV(V). The highest separation factor occurred in a $2.0 \mathrm{M} \mathrm{HCl}$ solution. The solvent extraction reaction of $\mathrm{Re}(\mathrm{VII})$ by $\mathrm{TBP}$ in a $2.0 \mathrm{M} \mathrm{HCl}$ solution was verified by applying a slope analysis method to the extraction data. The effect of adding $\mathrm{NaCl}$ to the synthetic solution led to a little increase in the extraction of both metals. At a concentration ratio of $\mathrm{Re}(\mathrm{VII})$ to $\mathrm{V}(\mathrm{V})$ between 0.1 to 60 , no $\mathrm{V}(\mathrm{V})$ was extracted by $\mathrm{TBP}$ in a $2.0 \mathrm{M} \mathrm{HCl}$ solution and thus complete separation was possible. The $\operatorname{Re}(\mathrm{VII})$ in the loaded TBP was completely stripped by a weak $\mathrm{HCl}$ solution of $\mathrm{pH} 3.0$.

\section{ACKNOWLEDGEMENTS}

This work was supported by the Global Excellent Technology Innovation of the Korea Institute of Energy Technology Evaluation and Planning (KETEP), granted financial resource from the Ministry of Trade, Industry \&Energy, Republic of Korea (No.20165010100880).

\section{REFERENCES}

1. Z. Lou, C. Guo, X. Feng, S. Zhang, Z. Xing, W. Shan, and
Y. Xiong, Hydrometallurgy 157, 199 (2015).

2. G. Hu, D. Chen, L. Wang, J. C. Liu, H. Zhao, T. Liu, T. Qi, C. Zhang, and P. Yu, Sep. Purif. Technol. 125, 59 (2014).

3. H. H. Lai, C. C. Hsieh, C. M. Lin, and W. Wu, Met. Mater. Int. 22, 101 (2016).

4. A. Khoshnevisan, H. Yoozbashizadeh, M. Mohammadi, and A. Abazarpoor, Miner. Metall. Proc. 30, 53 (2013).

5. K. H. Park, D. Mohapatra, B. R. Reddy, and C. W. Nam, Int. J. Miner. Process. 80, 261 (2006).

6. R. R. Srivastava, M. S. Kim, and J. C. Lee, J. Chem. Technol. Biotechnol. 90, 1752 (2016).

7. C. D. Anderson, P. R. Taylor, and C. G. Anderson, Miner. Metall. Proc. 30, 59 (2013).

8. L. Zeng and C. Y. Cheng, Hydrometallurgy 98, 1 (2009a).

9. H. T Truong and M. S. Lee, Geosystem Eng. 20, 224 (2016).

10. Y. A. El-Nadi, N. S. Awwad, and A. A. Nayl, Int. J. Miner. Process. 90, 115 (2009).

11. T. H. Nguyen and M. S. Lee, J. Korean Inst. Resour. Recy. 22, 3 (2013).

12. M. Hosseinzadeh, M. Alizadeh, M. Ranjbar, and M. Pazouki, IJE Trans. A: Basics. 27, 651 (2014a).

13. M. Hosseinzadeh, M. Alizadeh, and M. Ranjbar, Int. J. Miner. Process. 130, 88 (2014b).

14. A. M. Petrova and A. G. Kasikov, Hydrometallurgy 165, 270 (2016).

15. T. Sato, S. Ikoma, and T. Nakamura, J. Inorg. Nucl. Chem. 39, 395 (1977).

16. D. Schrotterova and P. Nekovar, Chem. Pap. 60, 427 (2006).

17. D. H. Yang, R. R. Srivastava, M. S. Kim, D. D. Nam, J. C. Lee, and H. T. Huynh, Met. Mater. Int. 22, 897 (2016).

18. W. Li, Y. Zhang, T. Liu, J. Huang, and Y. Wang, Hydrometallurgy 131-132, 1 (2013).

19. A. Nakajima, Talanta 57, 537 (2002).

20. Y. Chen, Q. Feng, Y. Shao, G. Zhang, L. Ou, and Y. Lu, Int. J. Miner. Process. 79, 42 (2006).

21. L. Lou, L. Kejun, A. Shibayama, W. Yen, T. Fujita, O. Shindo, and A. Katai, Hydrometallurgy 72, 1 (2004).

22. R. R. Srivastava, M. S. Kim, J. C. Lee, and S. Ilyas, Hydrometallurgy 157, 33 (2015).

23. L. Zeng and C. Y. Cheng, Hydrometallurgy 98, 10 (2009b).

24. Y. Liu, H. S. Jeon, and M. S. Lee, Korean J. Met. Mater. 54, 592 (2016).

25. T. Sato, S. Ikoma, and T. Nakamura, Hydrometallurgy 6, 13 (1980).

26. T. Sato and K. Sato, Hydrometallurgy 25, 281 (1990).

27. B. Heshmatpour and R. E. Mcdonald, J. Less Common Met. 86, 121 (1982).

28. T. H. Nguyen and M. S. Lee, J. Korean Inst. Resour. Recy. 25, 16 (2016).

29. H. T. Truong and M. S. Lee, Korean J. Met. Mater. 55, 405 (2017). 
30. Z. S. Abisheva, A. N. Zagorodnyaya, and N. S. Bekturganov, Hydrometallurgy 109, 1 (2011).

31. E. K. Alamdari, D. Darvishi, D. F. Hagshenas, N. Yousefi, and S. K. Sadrnezhaad, Sep. Purif. Technol. 86, 143 (2012).

32. R. R. Srivastava, M. Kim, J. Lee, M. K. Jha, and B. Kim, J. Mater. Sci. 49, 4671 (2014).

33. O. P. Kalyakina, O. N. Kononova, S. V. Kachin, and A. G. Kholmogorov, Bull. Korean Chem. Soc. 25, 79 (2004).

34. J. Bassett, R. C. Denney, G. H. Jeffery, and J. Mendham,
J., 4th edition, Longman, London and New York (1939).

35. S. Y. Lee and P. Nash, J. Mater. Sci. 28, 1946 (1993).

36. C. Z. Fang, Z. Hong, and Q. Z. Hui, Hydrometallurgy 97 , 153 (2009).

37. D. J. Pruett and D. R. Mctaggart, Sep. Sci. Technol. 17, 1091 (1982).

38. R. R. Srivastava, J. C. Lee, and M. S. Kim, Ind. Eng. Chem. Res. 55, 8191 (2016).

39. J. G. Ahn and M. S. Lee, Korean J. Met. Mater. 53, 488 (2015). 